\title{
Gestão, formação docente e inclusão: eixos da reforma educacional brasileira que atribuem contornos à organização escolar
}

\author{
Maria Helena Michels \\ Universidade Federal de Santa Catarina, \\ Departamento de Estudos Especializados em Educação
}

\section{Introdução}

O presente trabalho tem como tema a organização escolar a partir da reforma educacional brasileira nos anos de 1990. O objetivo principal é discutir as formas organizativas que a política educacional atual indica à escola. Para tanto, parto da hipótese de que a atual proposição política para a educação se sustenta em três eixos, quais sejam, gestão, formação de professores e inclusão, que, articulados entre si, atribuem à escola uma nova organização.

Para discutir tais questões faz-se premente apresentar, ainda que brevemente, o papel que a escola desempenha hoje na sociedade. Compreendo que a escola, como parte constituinte da sociedade moderna, assume papel relevante na consolidação de determinados "traços" sociais.

A instituição escolar pode ser compreendida como um espaço social privilegiado onde, concomitantemente, são socializados saberes sistematizados e transmitidos valores por ela legitimados. Para Giroux e Simon (1995, p. 95),

\begin{abstract}
[...] as escolas são formas sociais que ampliam as capacidades humanas, a fim de habilitar as pessoas a intervir na formação de suas próprias subjetividades e a serem capazes de exercer poder com vistas a transformar as condições ideológicas e materiais de dominação em práticas que promovam o fortalecimento do poder social e demonstrem as possibilidades de democracia.
\end{abstract}

Ao mesmo tempo, a escola assume potencialmente o papel de transformar a sociedade. Portanto, ela é produto e produtora das relações sociais. Então, que papel vem sendo desempenhado por ela no atual momento histórico?

Segundo Paro (2001, p. 10),

Não há dúvida de que podemos pensar na escola como instituição que pode contribuir para a transformação social. Mas, uma coisa é falar de suas potencialidades... uma coisa é falar "em tese", falar daquilo que a escola poderia ser. [...] outra coisa bem diferente é considerar que a escola que aí está já esteja cumprindo essa função. Infelizmente 
essa escola é sim reprodutora de certa ideologia dominan-

te... é sim negadora dos valores dominados e mera

chanceladora da injustiça social, na medida em que recoloca

as pessoas nos lugares reservados pelas relações que se dão

no âmbito da estrutura econômica.

Contudo, além das funções política e social assumidas pela escola, faz-se necessário explicitar que estas são "atravessadas pelos interesses das classes sociais" (Vieira, 2000, p. 130). As instituições de ensino selecionam e privilegiam determinados saberes em detrimento de outros, em que valores, normas e costumes respondem, pela ótica de Bourdieu e Passeron (1992), aos interesses de grupos e classes dominantes. Tais classes selecionam os saberes que devem ser transmitidos às gerações mais novas (apregoados na escola por meio do currículo prescrito e do currículo oculto); expressam a maneira muitas vezes desigual pela qual a escola deve organizar-se para atender as diferentes crianças, jovens e adultos; determinam as distintas escolas para diferentes pessoas, entre outros pontos que fazem da escola uma instituição com possibilidades e limites para transformar a sociedade.

Como veremos mais adiante, a escola hoje é conclamada a ser democrática, "para todos", uma escola inclusiva. Porém, se não levarmos em consideração os aspectos apresentados anteriormente, corremos o risco de fazer uma análise ingênua sobre seu papel social.

Desta maneira, para estudar a escola e sua organização, faz-se necessário relacioná-la aos aspectos mais amplos da sociedade como, por exemplo, a economia e a política, sem perder de vista a troca existente entre esses elementos e o cotidiano escolar.

Levando em conta tais considerações, parto da compreensão de que a atual reforma educacional se esforça para promover mudanças, porém não propõe a transformação da própria escola, uma vez que mantém as relações já existentes. Podemos pressupor que os três eixos indicados anteriormente como organizadores da reforma em curso atribuem contornos à nova organização escolar, sem mudar a sua essência.
Na gestão, observa-se o destaque dado à descentralização. A escola passa a ser o "foco" da gestão administrativa e financeira, sendo responsabilizada pelo sucesso ou fracasso dessa política.

Nessa perspectiva, os professores são considerados os gestores da educação e da escola. Sua formação deve adquirir caráter prático e instrumental. E uma das tarefas destinadas a esses sujeitos é a inclusão dos alunos que historicamente foram excluídos da escola.

A inclusão, então, aparece como propulsora de uma nova visão da escola. Agora sob a narrativa do respeito às diferenças, oportuniza-se educação diferente para "compensar" as diferenças sociais.

\section{A reforma e a organização escolar}

A atual reforma educacional, que se inicia no Brasil nos anos de 1990, tem como um de seus marcos a elaboração do Plano Decenal de Educação (previsto para vigorar de 1993 a 2003). Este plano derivou da Conferência Mundial sobre Educação para Todos, realizada em Jomtien, Tailândia, em 1990. Outros eventos e seus respectivos documentos passam a indicar a necessária reforma educacional brasileira. Percebe-se, nesse movimento, a influência de organismos internacionais na proposição política para a educação nacional. ${ }^{1}$ Para Torres (1996), o Banco Mundial destaca-se entre as várias agências ao apresentar uma proposta articulada em relação à educação nos países em desenvolvimento que abrange "das macropolíticas até a sala de aula" (p.126).

Entretanto, isso não significa a assimilação passiva dos preceitos internacionais, pois, segundo Ozga (2000), a política educacional constitui-se em um "terreno de contestação". E, como já afirmamos (Michels, 2004, p. 44), é nesse terreno que

1 Sobre a influência de organismos internacionais na reforma educacional, ver Tommasi, Warde e Haddad (1996), Warde (1998), Fonseca (1995), Shiroma, Moraes e Evangelista (2000), entre outros. 
[...] os sujeitos envolvidos não tomam a política como algo pronto e acabado. Ao contrário, por mais que as legislações e as normas instituídas conformem práticas, estas serão apreendidas por sujeitos que darão vida a estes encaminhamentos políticos. Os sujeitos envolvidos entendem as indicações políticas de maneira distinta, conforme suas vivências, seus interesses, sua organização profissional, entre outros. Cada instituição educacional acaba por "implementar" as políticas à sua maneira [...].

É no embate entre a proposição política e o cotidiano da escola que esta vai constituindo-se e organizando-se. É justamente nessa relação que se faz importante refletir sobre a política educacional em curso e o papel atribuído à educação e à escola no Brasil.

As reformulações apresentadas nessa reforma educacional atingem a organização da educação brasileira, principalmente a partir da lei n. 9.394/96 (Lei de Diretrizes e Bases da Educação Nacional LDBEN). ${ }^{2}$ Com esta lei, segundo seu artigo 21, “A educação escolar compõe-se de: I - educação básica, formada pela educação infantil, ensino fundamental e ensino médio; II - educação superior". Constituem ainda a educação básica a educação de jovens e adultos e a educação profissional. A educação especial é reconhecida no artigo 58 como "modalidade de educação escolar oferecida preferencialmente na rede regular de ensino, para educandos portadores de necessidades especiais" (Brasil, 1996).

Por compreender a política educacional como uma política pública, considero que, por meio dela, os governos definem, organizam, materializam mudanças para a área em questão. ${ }^{3}$ Porém, as políticas educacionais não estão sozinhas na sociedade. Ao

2 Faz-se importante considerar que tanto a LDBEN como o Plano Nacional de Educação contaram com disputas de diferentes projetos. Em ambos os casos, os conservadores e privatistas saíram vencedores.

3 Para efeito deste artigo, entendo "política pública" como a "materialidade" da intervenção do Estado ou, em outras palavras, os recursos disponíveis pelo Estado para materializar definições e encaminhamentos para a sociedade (Azevedo, 1997). contrário, relacionam-se de maneira intrínseca à realidade social mais ampla. Nesta perspectiva, as mudanças que ocorrem na sociedade buscam na educação um alicerce.

As reformas sociais em curso propõem mudanças em relação a diferentes aspectos. Um deles diz respeito à reforma do Estado. Para a manutenção do capitalismo, o neoliberalismo (ou neoconservadorismo) vem propondo modificações em relação ao papel que o Estado deve desempenhar. Este deixa de ser um "Estado intervencionista" e de bem-estar (lembrando que este último não se consolidou no Brasil de maneira efetiva) para constituir-se em um "Estado regulador".

O Estado, até então burocratizado e maximizado como provedor, cede lugar a um Estado mínimo para prover, mas máximo para regular e gerenciar. Essa indicação do novo papel do Estado coloca a necessidade de a sociedade civil organizar-se para prover o que o Estado abandona e pelo que não mais se responsabiliza. Este último, porém, regula/gerencia o que a sociedade civil oferece.

Em relação à educação, e especificamente sobre o trabalho na escola, a mudança no papel do Estado pode ser pensada por, no mínimo, dois pontos:

a) o Estado retrai-se na provisão, destacando o papel da unidade escolar como responsável pela educação das crianças, jovens e adultos, mas mantendo o controle do que é feito pela escola por meio da avaliação (SAEB - Sistema de Avaliação da Educação Básica, ENEM - Exame Nacional do Ensino Médio, ENC - Exame Nacional de Cursos);

b) a retirada do Estado como provedor se dá mediante a entrada da sociedade civil nas unidades escolares para auxiliar na resolução de problemas, principalmente por meio de programas como, por exemplo, o Programa Amigos da Escola e o Programa Adote um Aluno.

Tais pontos indicam que a mudança no papel do Estado leva a alterações nas relações dentro da esco- 
la, com a entrada nesse espaço de pessoas a desempenharem funções que historicamente cabiam aos professores; com o controle do que é trabalhado dentro de sala de aula, com base nos resultados que os alunos apresentam nas avaliações externas ao processo ensino-aprendizagem; com a necessária articulação entre escola e comunidade, porém agora com esta última sendo chamada a "resolver", juntamente com a escola, os problemas mais imediatos (principalmente os relacionados à manutenção financeira da escola).

Autores como Ferraro (1999), Ferraro e Machado (2002) e Freitas (2004; 2002) vêm mostrando em seus estudos que, a partir dos anos de 1990, se por um lado tem ocorrido um aumento no número de matrículas no ensino fundamental, por outro há uma queda de desempenho dos alunos desse nível de ensino.

Objetivando universalizar o ensino fundamental, a atual reforma educacional brasileira imprimiu algumas alterações no processo ensino-aprendizagem, modificando, por exemplo, a organização do tempo da escola.

Conforme Freitas (2004, p. 4), “[...] em 2002 o censo escolar nacional indicava a existência de $82 \%$ de escolas organizadas em séries, 10,9\% organizadas unicamente em ciclos e $8,5 \%$ organizadas em séries e ciclos".

Como se pode observar, a seriação é a maneira mais usual de organizar a escola e, ao mesmo tempo, tal organização vem sendo alvo de críticas por, principalmente, excluir de seu sistema um contingente muito grande de alunos, sobretudo aqueles das classes populares.

Com um currículo rígido e uma avaliação centrada nos resultados, as escolas seriadas vêm dando mostra de sua incapacidade para ensinar muitas crianças e jovens que, não se adaptando aos modelos rígidos impostos por essa instituição, ou não chegam à escola ou dela se evadem após anos de "insucesso". ${ }^{4}$

Baseando-se na crítica à rigidez da escola seriada, iniciaram-se no Brasil, principalmente em alguns

\footnotetext{
4 A este respeito, ver Ferraro (1999) e Freitas (2002).
}

municípios cuja gestão era de oposição ao governo federal, experiências de organização de escolas em ciclos. Tais experiências foram apreendidas pela política educacional, sem, no entanto, provocar mudanças significativas no interior da escola.

Se, por um lado, a organização por série tem como um de seus principais problemas a rigidez de tempo, do currículo e da avaliação, que levam a altos índices de fracasso na escola e a conseqüente evasão, por outro lado, a organização por ciclos flexibiliza o tempo, o currículo e a avaliação durante o período do ciclo. Mas no término de cada ciclo essa inflexibilidade reassume o processo ensino-aprendizagem, levando, em muitos casos, ao fracasso. Outro ponto a ser destacado é o de que se flexibilizam tanto os componentes do processo ensino-aprendizagem que se acaba por proporcionar educação diferente para pessoas diferentes.

Para Correia (2004, p. 13),

$\mathrm{Na}$ realidade, ao promover o elogio incontrolado da flexibilidade organizacional como a única alternativa credível à intervenção homogeneizante e burocrática do Estado e ao eleger a flexibilidade curricular como norma capaz, de per si, assegurar o ajustamento da acção educativa às necessidades diversificadas dos seus destinatários, e não cuidando, portanto, dos efeitos sociais induzidos por estes dois preceitos, a "ideologia da inclusão" é particularmente insensível aos efeitos de hierarquização de que ela é responsável.

Podemos, nessa lógica, cair na armadilha segundo a qual, em nome do respeito à diferença, os alunos sejam excluídos de seu direito ao conhecimento.

Para Freitas (2004, p. 22),

Pode-se dizer que quanto mais se falou em inclusão mais se legitimou a exclusão social construída previamente à escolarização, por um mecanismo dissimulatório de inclusão formal na escola que transmutou a exclusão escolar objetiva (repetência, evasão) em exclusão escolar subjetiva (auto-exclusão entre ciclos, "opções" por trilhas de progressão menos privilegiadas, trânsito formal sem domínio 
real), a partir dos horizontes e possibilidades de classe previamente interiorizados pelas condições objetivas de vida na sociedade.

Esse mesmo autor nos indica que "Parece que estamos diante de um fenômeno antigo e resistente" (idem, p. 18), pois a escola não conseguiu superar o problema que historicamente está posto para ela, qual seja, ensinar todas as crianças e jovens. O papel que o Estado vem desempenhando, então, é o de consolidar as desigualdades sociais por meio da escola.

Nesta relação podemos inferir que a reforma educacional no Brasil perpassa por alguns pontos cruciais como a gestão, o financiamento, a avaliação, a formação de professores, o currículo, a inclusão. Para efeito deste estudo, passaremos a analisar três desses pontos que se apresentam de maneira fulcral para o debate em torno da reforma e da organização da educação no Brasil: a gestão, a formação de professores e a inclusão.

\section{Organização escolar: a gestão, a formação docente e a inclusão}

\author{
A gestão como organizadora \\ da educação e da escola
}

A reforma educacional iniciada no Brasil nos anos de 1990 assume a racionalidade administrativa como paradigma. Para Oliveira (2000, p. 331), "as reformas educacionais dos anos 90 apresentam como seu principal traço a tentativa de 'modernização' administrativa do aparato público".

Tendo por base a crítica ao modelo centralizado de planejamento, a reforma de Estado iniciada no Brasil nos anos de 1990 vem substituindo o planejamento centralizado pela flexibilização da gestão. De acordo com Oliveira (2002, p. 87-88),

\section{Contra o planejamento centralizado em mãos de tec-} nocratas, contrapõe-se o poder local das comunidades, antes ignoradas pelos planejadores. As soluções buscadas parecem não mais ancorar-se no planejamento centralizado, realizado por técnicos capacitados, mas no mercado, nas relações de competitividade, únicas capazes de instaurar a excelência em espaços antes dominados pelo paternalismo ineficiente.

Na reforma educacional, esse planejamento apresenta-se de maneira flexibilizada, indicando um novo modelo de gestão do ensino público. Agora descentralizada, a gestão deve assumir uma forma mais flexível e participativa.

A flexibilização como marca desses modelos da gestão

[...] se por um lado incorpora antigas conquistas dos movimentos organizados e das resistências dos trabalhadores às formas capitalistas de organização e gestão do trabalho, por outro, o fazem atribuindo-lhes novos significados, o que faz com que tenham na aparência conteúdos mais consensuais, mas na sua prática efetiva conservem pressupostos autoritários. (idem, p. 95-96)

Nessa perspectiva, o processo de municipalização, presente não somente na política educacional mas em praticamente toda a área social, assume lugar de destaque. Rosar (2002, p. 136) alerta para o fato de que

As evidências, ao longo das últimas décadas, em termos do funcionamento do sistema educacional, permitem avaliar que o processo de descentralização pela via da municipalização, induzida pelo governo federal, produziu um efeito desagregador das redes municipais, afetando diretamente a expansão e a qualidade do ensino.

Sem sombra de dúvida, a municipalização vem sendo utilizada pelo governo federal muito mais como um processo que possibilita à União o repasse do encargo sobre a educação básica. Para Portela de Oliveira (2002), "a municipalização é, certamente, a transferência de encargos de uma esfera à outra, mas isso não significa, necessariamente, um processo de 'democratização', sentido com o qual é positivamente percebido pelo senso comum". 
Nessa linha de raciocínio, a escola passa a ser o "foco" da gestão administrativa e financeira. Para Oliveira (2000, p. 95-96),

\footnotetext{
A lógica assumida pelas reformas estruturais que a educação pública vai viver no Brasil em todos os âmbitos (administrativo, financeiro, pedagógico) e níveis (básica e superior) tem um mesmo vetor. Os conceitos de produtividade, eficácia, excelência e eficiência serão importados das teorias administrativas para as teorias pedagógicas.
}

Salienta-se que a busca por autonomia pedagógica das escolas públicas foi uma luta constante da comunidade escolar, das organizações representativas dos profissionais da educação, de intelectuais de esquerda, entre outros, principalmente nos anos de 1970-1980. Buscava-se, naquele momento, a autonomia escolar para a construção dos projetos políticopedagógicos. Em nome dessa "autonomia", a política educacional propõe a gestão escolar, descentralizando não a proposta educacional, mas a sua administração e seu financiamento.

Atrelada a critérios de produtividade, a reforma educacional atribui significativa relevância aos processos avaliativos, que continuam centralizados na União. Desta maneira, podemos pensar que essa proposta de gestão articula financiamento e avaliação como principais instrumentos (Oliveira, 2000). Para essa autora,

[...] as reivindicações por maior autonomia para as escolas têm sido respondidas pelo Estado como possibilidade de descentralização administrativa e financeira. A autonomia pedagógica, compreendida como liberdade de cada escola construir o seu projeto pedagógico, tem caráter limitado já que, em muitos casos, tais projetos são elaborados de acordo com critérios de produtividade definidos previamente pelos órgãos centrais e garantidos pelos processos de avaliação. (p. 104)

Com uma narrativa articulada à democratização da educação, o governo brasileiro vem fazendo o que Melo (2000, p. 246) denomina "compartilhar a ges- tão", ou seja, divide a responsabilidade de prover a educação com a sociedade civil. Mas não abre mão de definir como deve ser conduzida a educação da maioria da população brasileira. Este modelo de gestão mantém o planejamento e o controle dos resultados no poder central. Ao mesmo tempo, descentraliza a administração da implementação das propostas com as unidades escolares e sua comunidade. Para Oliveira (2004), essa estratégia leva a escola a conseguir complementar seu orçamento com recursos oriundos de sua própria comunidade.

Com a indicação de que o problema financeiro da educação se centrava na utilização dos recursos a ela destinados, e não no seu montante, o Estado propõe uma gestão compartilhada dos investimentos. Tal gestão possibilita a captação de recursos e, simultaneamente, promove o envolvimento da sociedade civil no cotidiano da escola.

Nessa perspectiva, o modelo de gestão indicado pelo Estado necessita da "ideologia inclusiva", da qual nos fala Correia (2004), para dar conta da manutenção da escola. Com o discurso de incluir todos os segmentos da sociedade na tarefa de educar as futuras gerações, o governo repassa a responsabilidade dessa educação aos seus próprios beneficiários.

Essas mudanças relacionadas à gestão chegam à escola e alteram sua organização e seu cotidiano. $\mathrm{Na}$ atualidade, a proposição tem sido descentralizar até chegar à escola. Nessa perspectiva, centra-se na unidade escolar a responsabilidade em "gerenciar" os problemas que esta e a comunidade ao seu entorno apresentam.

Partindo dessa perspectiva, faz-se necessário que os profissionais da educação, principalmente os professores, assumam a função de gestores da educação. Para tanto, tornou-se imperativo a focalização na formação desse profissional.

\section{O professor como "elo" de ligação entre a escola e a sociedade, e a sua formação}

Um outro ponto fulcral da reforma educacional em foco está colocado sobre o sujeito que é visto como 
o elo de ligação dessa política com a sociedade, qual seja, o professor.

Em vários documentos internacionais está destacada a importância do papel dos professores para responderem às demandas das "novas" tarefas da educação. A falta de preparo dos professores brasileiros é apontada, pelos órgãos oficiais, como uma das causas mais relevantes do insucesso escolar dos alunos.

Documento do Banco Mundial (1995) ressalta que a formação em serviço é uma estratégia eficaz para melhorar o conhecimento dos professores e, principalmente, diminui o custo dessa preparação. Com tal indicação, essa agência conota à educação caráter economicista e impõe uma visão utilitarista e fragmentada para a formação. A Comissão Econômica para a América Latina e o Caribe (CEPAL) também destaca a educação à distância como a forma mais apropriada de formar os docentes.

A maneira mais rápida e eficaz de melhorar a capacidade profissional dos professores é realizar programas especiais de capacitação docente, de fácil acesso, associados a adequado esquema de incentivos. Um bom exemplo seria um programa de educação à distância combinado com serviços de assessoria profissional, como parte de um plano de estudos que leve à obtenção de certificado profissional. (CEPAL/UNESCO, 1995, p. 259)

Tais proposições internacionais estão fortemente presentes no projeto de formação de professores apresentado pelo governo brasileiro. A formação docente ganha destaque na política educacional, principalmente a partir da promulgação das novas diretrizes e bases da educação nacional (LDBEN, lei n. 9.394/96), cujo artigo 62 preconiza que esta deva ocorrer

[...] em nível superior, em cursos de licenciatura, de graduação plena, em universidades e institutos superiores de educação, admitida como formação mínima para o exercício do magistério na educação infantil e nas quatro primeiras séries do ensino fundamental, e oferecida em nível médio, na modalidade normal. (Brasil, 1996)
A aprovação desta lei fez permanecer a ambigüidade quanto ao nível da formação: em nível médio ou nível superior para os professores da educação infantil e séries iniciais do ensino fundamental. ${ }^{5}$ Essa formação permanece na "eterna transitoriedade", como nos indica Carvalho (1997), ou seja, a formação de professores ocorrerá em nível superior quando houver condição para tal. Caso contrário, seja qual for a razão, essa formação poderá continuar ocorrendo no ensino médio.

Quanto ao locus de formação, podemos observar no artigo 62 da LDBEN que esta poderá ocorrer tanto nas universidades (em cursos de licenciatura plena) como nos institutos superiores de educação. Para essa lei (artigo 63):

$$
\begin{aligned}
& \text { Os institutos superiores de educação manterão: } \\
& \text { I - cursos formadores de profissionais para a educação } \\
& \text { básica, inclusive o curso normal superior, destinado } \\
& \text { à formação de docentes para a educação infantil e } \\
& \text { para as primeiras séries do ensino fundamental; } \\
& \text { II - programas de formação pedagógica para portadores } \\
& \text { de diplomas de educação superior que queiram se } \\
& \text { dedicar à educação básica; } \\
& \text { III - programas de educação continuada para os profis- } \\
& \text { sionais de educação dos diversos níveis. (Brasil, 1996) }
\end{aligned}
$$

Porém, após a promulgação da referida lei, o governo federal anuncia em 1999 o decreto n. 3.276, que atribui, em seu artigo $3^{\circ}$, parágrafo II, aos cursos normais superiores, dos institutos superiores de educação, exclusividade na formação de professores para a educação infantil e séries iniciais do ensino fundamental. Para Shiroma, Moraes e Evangelista (2000, p. 102),

[...] o curso de pedagogia perdeu a prerrogativa de formar o professor. Por decorrência, como reza o decreto, os centros, institutos, setores ou faculdades de educação são estimulados a oferecer cursos normais superiores e a

5 Em outro momento (Michels, 2004), estudei mais detidamente o caráter ambíguo da formação de professores. 
abandonar a formação docente em curso de pedagogia. Esse, a continuar existindo como previsto no art. 64 da LDBEN, deverá dedicar-se ao preparo de especialistas, particularmente gestores educacionais [...].

Com este decreto, a indefinição quanto à formação de professores e/ou de especialistas no curso de pedagogia parece ter sido solucionada. Entretanto, algumas regulamentações atreladas à LDBEN vão reforçar essa imprecisão, como veremos a seguir. Para Scheibe (2003), desde a promulgação, em 1996, da atual LDBEN, operou-se uma distinção entre a formação em nível universitário e a formação em nível não-universitário.

No ano 2000, com o decreto presidencial n. 3.554, e em 2001, por meio do parecer do Conselho Nacional de Educação (CNE) n. 133, o governo brasileiro indica que a formação dos professores poderia ocorrer nos cursos normais superiores e também nas universidades. ${ }^{6}$ Desta maneira, explicitou-se ainda mais a indefinição quanto ao locus de formação desses professores. Ou seja, no Brasil, hoje, os professores das séries iniciais do ensino fundamental e das modalidades de ensino podem ser formados tanto nos institutos normais superiores como nos cursos de pedagogia das universidades, além, é claro, da formação em nível médio.

Scheibe (2003, p. 8) afirma que

Normatizou-se uma hierarquia no interior do ensino superior e certamente não por acaso, estabeleceu-se como local preferencial para a formação dos docentes o nível mais baixo dessa hierarquia, uma solução que, independentemente do setor ao qual se vincula (pública, particular, comunitária), deverá ser a mais barata em todos os sentidos.

Essa hierarquização no processo de formação docente propicia a compreensão de que a política de for-

6 Essa substituição ocorre, em grande medida, pelas pressões advindas das universidades, especificamente dos cursos de pedagogia. mação de professores, quando possibilita dois âmbitos acadêmicos distintos de formação, reforça que esta ocorra no nível mais baixo - no caso, no nível médio.

Nos anos finais da década de 1990, assistimos a um aumento na procura pelos cursos de pedagogia. Para Campos (2004, p. 26-27), essa procura

\section{[...] estimulou secretarias estaduais de educação a for-} mulação de convênio com instituições, públicas e privadas, que por meio de programas especiais, em formatos variados - modular, parcelado, telepresencial à distância -, dedicaram-se à formação para as séries iniciais do ensino fundamental. De acordo com o Relatório Final da Comissão Assessora para a Educação Superior à Distância (MEC/EAD, 2002), "estima-se que essa exigência legal tenha motivado uma demanda pontual da ordem de 700 mil vagas".

Em grande medida, essa procura está associada à promulgação da nova LDBEN, que indicava, nas disposições transitórias, que a partir de 2007 todos os professores deveriam ter curso superior ou ser formados em serviço. ${ }^{7}$ Mas, por meio do parecer 01/03 do $\mathrm{CNE}$, indicou-se que houve uma leitura equivocada dessa lei e que, para os professores já em exercício, não haveria a obrigatoriedade dessa formação em nível superior.

Em 2006, o CNE aprova a Resolução n. 1, que institui as Diretrizes Curriculares Nacionais para o Curso de Pedagogia - Licenciatura (Brasil, 2006), na qual se observa desde a permanência de ambigüidades na formação até a centralidade do saber-fazer na sua proposição. Tal centralidade indica a influência dos ditames dos organismos internacionais na perspectiva da formação desse profissional.

Para dar ênfase ao papel do professor sem deixálo participar efetivamente das proposições, o gover-

7 Lei n. 9.394/96, título IX, "Das Disposições Transitórias”, artigo 87, parágrafo $4^{\circ}$ : “Até o fim da Década da Educação somente serão admitidos professores habilitados em nível superior ou formados por treinamento em serviço" (Brasil, 1996). 
no aponta algumas iniciativas para a formação de professores que podem ser sintetizadas em: flexibilização da formação; as competências a serem desenvolvidas; o aprender a aprender; atendimento à diversidade; centralidade da prática do professor, entre outras.

No que concerne à flexibilização, por exemplo, está expressa no locus, no nível de ensino em que a formação pode ocorrer e na modalidade em que será oferecida. Quanto ao locus, como já apontamos, podem-se formar professores nas universidades ou nos institutos normais superiores. Ao mesmo tempo, essa formação pode ocorrer em nível superior ou no ensino médio (conforme a própria LDBEN), a depender das condições existentes para tal (Michels, 2004); e ainda poderá ser oferecida por meio da formação em serviço ou do ensino à distância, ou, ainda, presencial.

Essa dicotomia da proposta de formação expressa uma política binária e não relacional (Torres, 1998). Essa perspectiva impele os professores das redes públicas, especificamente aqueles profissionais do ensino fundamental, a procurar sua formação em instituições que prometem formá-los em menos tempo, com menos gastos, entre outros pontos que caracterizam o aligeiramento da formação docente.

Quanto às competências, tão presentes nos documentos políticos, elas dizem respeito ao que o professor deve saber: trabalhar em parceria com a comunidade escolar, resolver problemas da escola, achar soluções criativas a problemas concernentes ao processo ensino-aprendizagem de seus alunos, até mesmo às situações da comunidade em que a escola está inserida.

Observa-se que essa proposição retira de cena as discussões sobre as condições de trabalho dos professores, como se elas estivessem resolvidas. A questão salarial, carga horária de trabalho, reconhecimento social desse profissional, entre outros elementos, não são mencionados pela política de formação docente. Ao contrário, essa política faz crer que basta a "boa vontade" dos professores para que os problemas educacionais se resolvam.

No caso brasileiro, especificamente nessa última reforma educacional, a formação docente está cen- trada na "prática" do professor. Isso poderia ser entendido como um "avanço" em relação a outras reformas educacionais do país. Contudo, tal centralidade aparece desvinculada da reflexão. Para Shiroma e Evangelista (2003, p. 89),

O cinismo da reforma está em que, ao mesmo tempo em que visa retirar a reflexão crítica da formação docente, anuncia como meta produzir o professor capaz de refletir sobre sua prática, conduzindo grande parte de nós a considerar que de fato isso se realizaria. Quais os efeitos dessa declaração? Pode-se sugerir que a reflexão, oferecida em abundância no plano discursivo, dificilmente se iria tornar objeto de reivindicação.

Além disso, podemos pensar que o que chamávamos, no Brasil, de formação de professores aparece hoje muito mais como treinamento profissional. Uma das modalidades de formação que está tendo forte expressão no país é a formação em serviço (além da formação à distância). Torres (1998, p. 177) indica:

De fato, o que está acontecendo é uma política de portas abertas a educadores leigos [...] dentro do sistema escolar. E é por essa razão que a capacitação em serviço vem adquirindo grande importância. O professor leigo ganha menos, não faz exigências trabalhistas e é fácil de descartar.

Tal perspectiva de formação docente leva a uma massificação dos níveis de ensino (principalmente o fundamental) sem a garantia de sua qualidade. Como formar o professor, então, para a chamada "educação para todos"? Qual formação de professores poderia indicar a inclusão como possibilidade para a escola do ensino fundamental?

\section{A formação de professores para a educação especial}

Tomaremos, aqui, a discussão sobre a formação de professores para a educação especial como expressão da formação em sua relação com a organização escolar. 
Na especificidade da educação especial, podemos afirmar que modificações têm sido implementadas em relação à formação de professores para a área. Estas relacionam-se às já mencionadas mudanças relativas à formação de professores do ensino fundamental.

Para a educação especial, a reforma em andamento prevê, na Resolução CNE n. 02/2001, que os professores que trabalham com alunos "que apresentam necessidades educacionais especiais" podem seguir dois modelos distintos: os capacitados e os especializados.

Tais modelos de professores são definidos nos parágrafos $1^{\circ}, 2^{\circ}$ e $3^{\circ}$ do artigo 18 (Brasil, 2001). No parágrafo $1^{\circ}$ definem-se as competências a serem desenvolvidas nos chamados professores capacitados:

$\S 1^{\circ}$ São considerados professores capacitados para atuar em classes comuns com alunos que apresentam necessidades educacionais especiais aqueles que comprovem que, em sua formação, de nível médio ou superior, foram incluídos conteúdos sobre educação especial adequados ao desenvolvimento de competências e valores para:

I - perceber as necessidades educacionais especiais dos alunos e valorizar a educação inclusiva;

II- flexibilizar a ação pedagógica nas diferentes áreas de conhecimento de modo adequado às necessidades especiais de aprendizagem;

III - avaliar continuamente a eficácia do processo educativo para o atendimento de necessidades educacionais especiais;

IV - atuar em equipe, inclusive com professores especializados em educação especial.

A formação dos professores capacitados, tanto em nível médio como superior, deve ocorrer por meio de oferecimento de disciplinas, ou tópicos, que venham a contemplar as discussões sobre a educação de alunos considerados deficientes. Percebe-se também que sua formação deve desenvolver, nesse futuro profissional, competências para executar atividades diretamente com os alunos considerados deficientes e, ao mesmo tempo, aprender a trabalhar em equipe.
Isso porque não serão esses os profissionais que irão planejar as atividades a serem desenvolvidas com esses alunos, mas sim os professores especializados. ${ }^{8}$

Já os professores especializados são os responsáveis pela organização das ações pedagógicas a serem desenvolvidas pelos "professores capacitados". Estes devem ter sua formação em nível superior ou em nível de especialização, como explicitado nos parágrafos $2^{\circ} \mathrm{e} 3^{\circ}$ do artigo 18 da LDBEN (Brasil, 1996):

$\S 2^{\circ}$ São considerados professores especializados em educação especial aqueles que desenvolveram competências para identificar as necessidades educacionais especiais para definir, implementar, liderar e apoiar a implementação de estratégias de flexibilização, adaptação curricular, procedimentos didáticos pedagógicos e práticas alternativas, adequadas aos atendimentos das mesmas, bem como trabalhar em equipe, assistindo o professor de classe comum nas práticas que são necessárias para promover a inclusão dos alunos com necessidades educacionais especiais.

$\S 3^{\circ}$ Os professores especializados em educação especial deverão comprovar:

I - formação em cursos de licenciatura em educação especial ou em uma de suas áreas, preferencialmente de modo concomitante e associado à licenciatura para a educação infantil ou para os anos iniciais do ensino fundamental;

II - complementação de estudos ou pós-graduação em áreas específicas da educação especial, posterior à licenciatura nas diferentes áreas de conhecimento, para

8 Como exemplo da formação de professores capacitados, podemos citar o Programa Educação Inclusiva: Direito à Diversidade. Nele, o Ministério da Educação, por meio da Secretaria de Educação Especial, desenvolve a formação de "gestores e educadores" para a educação inclusiva. Tal programa é organizado pelos chamados municípios-pólo, que atuam como multiplicadores, objetivando formar "gestores e educadores para atuar como multiplicadores no processo de transformação dos sistemas educacionais em sistemas educacionais inclusivos" (Informações obtidas em: 〈www.mec.gov.br/seesp>. Acesso em: 14 jul. 2005). 
atuação nos anos finais do ensino fundamental e no ensino médio.

Quanto aos professores que já estão exercendo o magistério, o parágrafo $4^{\circ}$ do artigo 18 especifica que lhes devem ser oferecidas "oportunidades de formação continuada, inclusive em nível de especialização, pelas instâncias educacionais da União, dos Estados, do Distrito Federal e dos Municípios" (idem).

A formação desse profissional, quando ocorrer em nível superior, deverá ser em cursos de licenciatura, especificamente no curso de pedagogia, como habilitação em educação especial, e não mais em uma de suas áreas definidas pela deficiência. ${ }^{9}$ Quando essa formação for oferecida em curso de especialização, poderá ocorrer em uma das áreas da deficiência ou estar relacionada com o atendimento educacional dos alunos deficientes, como, por exemplo, curso de especialização em educação inclusiva, em inclusão, entre outros.

Ou seja, segundo a Resolução CNE n. 02/2001, tanto os professores capacitados como os especializados podem ser formados em dois níveis. Os primeiros em nível médio ou superior, e os segundos em nível superior ou em pós-graduação. Também são formadores desses professores os cursos de complementação e de formação em serviço.

Durante a década de 1990, alguns cursos modificaram suas grades curriculares para todas as habilitações. Podemos citar como exemplo dessas modificações, especificamente para a habilitação educação

9 Mendes (2002) mostrou que em 2000 havia 31 cursos de pedagogia com habilitação em educação especial no país. Desses, somente um curso de licenciatura plena em educação especial não tinha vinculação com o curso de pedagogia - o Curso de Educação Especial da Universidade Federal de Santa Maria. Ainda não há referências sobre a formação de professores para a educação especial em cursos normais superiores. Ressalta-se ainda que a Resolução do CNE n. 01/2006, que institui as Diretrizes Curriculares Nacionais para o Curso de Pedagogia - Licenciatura, não faz referência a uma organização desse curso por habilitações. especial, as ocorridas na Universidade Federal de Santa Catarina (UFSC) (Michels, 2004) e na Faculdade de Educação da Universidade Estadual de Campinas (UNICAMP), estudada por Cartolano (1998).

Em nível de pós-graduação, Bueno (2002) mostra que esta formação contava, em 1998, com 43 cursos de especialização em educação especial, oferecidos pelas instituições de ensino superior (IES) no Brasil. A grande maioria desses cursos era destinada à educação especial de maneira geral e não se delimitava por categorias de deficiência.

Em relação à formação em cursos de pós-graduação stricto sensu, Bueno (2002, p. 52-53) informa: "Vinte e três IES indicaram possuir cursos de mestrado em educação que aceitam alunos interessados em desenvolver dissertações no campo da educação especial, sendo que somente duas delas mantêm mestrado específico em educação especial".

Entretanto, 35 IES não fazem indicações referentes a essa área específica em seus programas de mestrado em educação. Quanto à pós-graduação em nível de doutorado, "eram apenas 10 os cursos de doutoramento em educação que aceitavam, de alguma forma, alunos com interesses na educação especial [...]" (idem, p. 56).

Está presente na resolução do CNE n. 02/2001 que a formação continuada poderá ser a modalidade utilizada para formar os professores que já estejam atuando. Tal formação não é especificada quanto ao número de horas, e coloca a responsabilidade deste oferecimento aos estados e municípios.

Desta maneira, podemos notar a variação de níveis e tipos de formação de professores possibilitada pela atual legislação para a educação especial. Assim como para a educação regular, a proposta de formação de professores para a educação especial fortalece a tese de permanência e naturalização da ambigüidade quanto ao nível de formação.

A resolução do CNE n. 02/2001 também determina as competências necessárias para cada tipo de professor. Aos professores denominados capacitados cabe a tarefa de perceber quais são os possíveis alunos com necessidades educacionais especiais e de- 
senvolver com eles atividades ou ações pedagógicas em sala de aula. Aos professores especializados compete identificar esses alunos e definir estratégias que os professores capacitados deverão utilizar com eles em sala de aula.

Com essa resolução, então, é reforçada a divisão do trabalho dentro das escolas. Se anteriormente os professores especializados em atender os alunos considerados deficientes atuavam fora da escola regular, agora, com a política de inclusão, esses professores deveriam estar dentro das escolas, indicando o que deve ser feito pelos professores capacitados. Segundo Garcia (2004, p. 187),

A proposta de educação especial na educação básica, aqui analisada [Resolução CNE/CEB 2/2001] em sua relação com a formação de professores, opera pela justaposição de profissionais com formações diferençadas, como se a sua soma solucionasse as desigualdades educacionais que historicamente estão presentes nas proposições políticas para as escolas do ensino regular. A resposta apresentada contribui para administrar tais desigualdades, mas não as suplanta.

Pelas análises feitas anteriormente, percebemos que com a LDBEN e a Resolução CNE n. 02/2001 as ambigüidades na formação dos professores persistem. Esta imprecisão parece ser uma constante na formação dos docentes que vão, de uma maneira ou de outra, desenvolver trabalhos com alunos deficientes.

Quando a proposição de formação de professores para atender alunos com diagnóstico de deficiência se centra nas competências a serem desenvolvidas por esses profissionais, parece que se modifica tanto o papel do professor como o da escola.

Em síntese, podemos apreender que a proposição atual de formação de professores, tanto capacitados como especializados, não rompe com o modelo de formação tradicionalmente destinado à área. Com base nas contribuições de Skrtic (1996), é possível afirmar que a educação especial tem, historicamente, se organizado tendo por base o modelo médico-pedagógico. Este modelo chega mesmo a ser confundido com o conhecimento da educação especial e passa a organizar o currículo do curso de formação de seus professores, a indicar o trabalho a ser desenvolvido com os alunos considerados deficientes, a influenciar as políticas públicas voltadas à educação especial, entre outras ações que envolvem a área.

Alguns estudos nos fazem compreender que a dificuldade da área em aceitar a crítica a esse modelo médico-pedagógico está relacionada ao pensamento hegemônico, não somente na educação especial, mas na educação de maneira geral, que tem a base biológica como explicação para o insucesso escolar. ${ }^{10}$ Junto a ela, encontramos a sustentação psicológica de que o fracasso escolar decorre de questões individuais, e não sociais.

$\mathrm{Na}$ atualidade, a proposta de formação desses professores tem como máxima a inclusão. Porém, a manutenção da formação de professores com base no modelo médico-pedagógico auxilia nesse processo? Podemos pensar no processo de inclusão de alunos considerados deficientes formando professores, tanto capacitados como especializados, que centram o sucesso ou o fracasso dos processos de aprendizagem nos alunos individualmente? Além disso,

[...] se é verdade que, para a democratização da escolarização de alunos com deficiências por meio de sua inclusão no ensino regular, terão que ser superadas as barreiras impostas pelos educadores não-especializados e modificadas as práticas escolares na perspectiva da absorção, com qualidade, das mais diversas diferenças culturais, lingüísticas, étnicas, sociais e físicas, é também verdadeiro que a contribuição da área da Educação Especial não se fará presente enquanto permanecer hegemônico o modelo médico-pedagógico. (Michels, 2004, p. 158-159)

Desta maneira, podemos inferir que a formação de professores proposta hoje pela política educacional brasileira não possibilita a superação da exclu-

${ }^{10}$ Ver, entre outros, Nunes et al. (1999), Soares (1999), Michels (2004). 
são. Ao contrário, tal proposição consolida a exclusão dos alunos das classes populares, sendo eles considerados deficientes ou não, no seio mesmo da escola. Não mais falamos em excluídos da escola (do ensino fundamental), mas em excluídos do processo de aprendizagem no interior da escola.

\section{A inclusão como política}

É no decorrer da década de 1990 que ocorre no Brasil a apropriação do discurso internacional relacionado à inclusão. Alguns pontos passaram a fazer parte desta discussão, dos quais se destacam a questão da política de inclusão, a flexibilização curricular, a preparação da escola regular para receber os alunos considerados deficientes, técnicas e recursos que auxiliam nessa ação, e ganharam ênfase o professor, como o agente principal desse processo de inclusão, e a sua formação.

A atual política de inclusão, que, segundo Correia (2004), vem "tomando corpo" nos últimos dez anos, não se refere somente à entrada dos alunos considerados deficientes no ensino regular, mas se constitui, mesmo, em uma narrativa que é incorporada pelo campo educacional como "ideologia da inclusão".

A partir dessa lógica, a escola regular precisa organizar-se para receber todas as crianças cujas diferenças sejam ou não explícitas. Porém, compreendo que tais diferenças são determinadas também por questões sociais, e não especificamente por diferenças individuais.

Para Martins (1997), a inclusão, nessa sociedade, ocorreria por uma via marginal, e a questão da exclusão constitui-se em um falso problema. Em suas palavras: "O discurso corrente sobre exclusão é basicamente produto de um equívoco, de uma fetichização, a fetichização conceitual da exclusão, a exclusão transformada numa palavra mágica que explica tudo" (p. 27).

Correia também nos adverte para o fato de que

[...] a noção de exclusão social tornou-se numa espécie de "lugar comum" que designa um conjunto heterogéneo de fenómenos sem os discriminar numa lógica em que a simples designação do fenómeno parece fazer a economia da sua explicação e da justificação das modalidades de intervenção social desenvolvidas. (2004, p. 1)

No Brasil, a discussão sobre exclusão e a "urgente" inclusão dos grupos minoritários em serviços e espaços vem ganhando relevância. Segundo Martins (2000, p. 11), "não estamos em face de um novo dualismo, que nos proponha as falsas alternativas de excluídos ou incluídos. A sociedade que exclui é a mesma sociedade que inclui e integra, que cria formas também desumanas de participação, na medida em que delas faz condições de privilégios e não de direitos".

Podemos considerar, então, que a exclusão e a inclusão são "representações" dos processos sociais excludentes e includentes, típicos da sociedade capitalista. Uma só existe em relação à outra. Ou seja, "A inclusão só pode ser pensada pela presença constante da exclusão" (Michels, 2004, p. 31).

A inclusão somente pode ser vista como "possibilidade" para os excluídos em uma sociedade excludente. Quando lidamos com a exclusão sem sujeito histórico, como a reforma educacional atual propõe, esta esvazia-se de sentido e de luta. Para Martins (2000, p. 18),

Essa interpretação de fundo positivista reinstaura o escalonamento do processo histórico, relegando ao passado e ao residual aquilo que supostamente não faria parte do tempo da modernidade, como o tradicionalismo dos pobres migrados do campo para a cidade, a cultura popular e a própria pobreza. Seriam manifestações anômalas e vencidas de uma sociabilidade extinta pela crescente e inevitável difusão da modernidade que decorreria do desenvolvimento econômico e da globalização.

Se retomarmos a questão da formação de professores, como podemos pensar em formar os professores para trabalharem com alunos que "teimam em fazer parte daquilo que não os quer senão como vítimas e beneficiários residuais de suas possibilidades?" (idem, p. 11). 
Tomando a educação dos sujeitos considerados deficientes como expressão dessa discussão, podemos afirmar que há maneiras distintas de se apropriar desse debate. A partir de leituras das principais publicações da área, foi possível perceber que há divergências relacionadas à apreensão da política de inclusão. Identifiquei, em relação a esta proposição, especificamente relacionada aos alunos deficientes, que há, ao menos, duas tendências neste debate. A primeira delas diz respeito à perspectiva que chamarei de propositiva; a segunda denominarei analítica.

A perspectiva propositiva compreende as produções que: a) tomam a inclusão como um modelo predefinido; b) propõem indicações explícitas de como deve ocorrer a inclusão; c) a partir da sensibilização dos professores, indicam que estes devem ter desenvolvido suas competências para incluir os mais diferentes alunos; e d) discutem a inclusão sem levar em conta as suas reais possibilidades.

Alguns autores tratam a inclusão de alunos considerados deficientes como um problema restrito das competências dos professores. Centram essa discussão nas questões específicas relacionadas à deficiência e pouco discutem a imprescindível tarefa de ensinar esses alunos. Como expressão dessa perspectiva, reproduzo um excerto de Sassaki (1997, p. 126) no qual o autor apresenta uma lista indicando o que o professor deverá fazer para incluir um aluno considerado deficiente na rede regular de ensino:

Para com estudantes com impedimento auditivo, o professor deverá:

- Sentar-se na frente da sala.

- Usar recursos visuais.

- Falar claramente.

- Se o estudante usa a língua dos sinais, aprender os sinais e estimular outros estudantes a aprendê-los também.

Para com estudantes com distúrbio de comportamento, o professor deverá:

- Aplicar técnicas de modificação de comportamento.

- Designar responsabilidades especiais.

- Identificar os pontos fortes deles.
- Ignorar comportamentos inadequados, quando possível.

- Focalizar os pontos bons e elogiá-los.

- Formar grupos de aprendizado cooperativo com instruções e metas bem claras. ${ }^{11}$

A perspectiva propositiva parece tomar a inclusão como objetivo primeiro e último, afirmando-se pela ausência de análise sobre as relações sociais concretas que expliquem a atualidade. Quando é feita referência à materialidade, busca-se nela o que está certo ou errado nos encaminhamentos mais imediatos. Essa articulação também pode ser observada na ênfase dada à sensibilização necessária ao professor para que este "faça" a inclusão. Outro aspecto é a centralidade no professor como o sujeito responsável pelo sucesso ou fracasso desse "encaminhamento" inclusivista.

Já as obras que: a) analisam a possibilidade de inclusão levando em consideração as questões sociais mais amplas (história, política, economia); b) discutem a educação especial articulada ao debate da educação geral; e c) investigam a proposição inclusiva para a área fazendo uma análise crítica desse momento histórico, compõem a perspectiva chamada aqui de analítica.

Nas produções consideradas analíticas, encontramos a compreensão de que a história (da sociedade, da educação e da educação especial) é a base para desenvolver um exame cuidadoso da atualidade. Nessa perspectiva, a materialidade das condições históricas e sociais para a inclusão é que possibilita a discussão sobre ela.

A inclusão, então, deve ser analisada à luz das suas reais possibilidades, sem ser tomada como único objetivo. O movimento da sociedade é que possibilita, em maior ou menor grau, a inclusão. Ao mesmo tempo, nessa perspectiva, alunos e professores são sujeitos constituintes e constituidores desse processo, e não vítimas de decisões do "sistema".

${ }^{11} \mathrm{O}$ autor segue com a lista de indicações do que o professor deverá fazer para alunos com dificuldade de aprendizagem, impedimentos visuais, limitações motoras e deficiência mental. 
Não podemos, contudo, pensar que essas duas perspectivas existem de maneira tão clara e explícita, sem que uma influencie na produção da outra. Ao contrário, elas influenciam-se mutuamente e coexistem na educação especial, no âmbito da produção de conhecimento sobre a inclusão de alunos considerados deficientes, sendo provável que também se façam presentes no debate sobre inclusão de maneira geral.

Tendo um caráter mais técnico e organicista, a tendência propositiva parece indicar uma determinada maneira de compreender a educação especial e os sujeitos a ela relacionados.

Consolidando o tratamento diferente para as desigualdades produzidas pela própria sociedade capitalista, a perspectiva propositiva faz da inclusão um processo perverso, uma vez que celebra a diferença que exclui. Porém, como já indiquei em outra ocasião (Michels, 2004, p. 35),

[...] é no bojo desse pensamento positivista, de encaminhamento tecnicista e organicista, que nasce outra maneira de entender a relação entre a sociedade e a deficiência. É, justamente, da sua negação que emerge a compreensão de que é necessário pensar o fenômeno da deficiência nas relações produzidas por esta sociedade. É dessa relação que surge a compreensão de que fizemos parte dessa organização, reafirmando-a ou negando-a. Esse encaminhamento desvitima o sujeito, colocando-o como propositor nessa relação.

A partir das análises realizadas, podemos inferir que a reforma educacional, iniciada nos anos de 1990, se aproxima da perspectiva propositiva. Esta traz em sua essência, ainda que de maneira dissimulada, a manutenção da exclusão social. Porém, agora, essa exclusão abandona a forma objetiva (vista na educação por meio da evasão e repetência, principalmente) e configura-se na exclusão subjetiva (Freitas, 2002). Esta última apresenta-se de maneira mais perversa que a primeira, pois deposita no próprio excluído a responsabilidade de sua condição.

\section{Considerações finais}

As reflexões aqui apresentadas, cuja temática foi a organização escolar, tiveram por objetivo discutir como a reforma educacional brasileira, que se iniciou nos anos de 1990, tem proposto uma (re)organização escolar.

Partimos da compreensão de que a reforma direcionada à área educacional está atrelada a uma reestruturação do próprio sistema capitalista, que, com sua crise evidenciada, sobretudo nos anos de 1980, necessitava reorganizar-se, porém sem mudar suas bases.

Nesse contexto, os organismos internacionais (principalmente o Banco Mundial) orientam as reformas por algumas diretrizes, dentre as quais se destaca o papel do Estado, a educação e a escola.

O papel do Estado é redimensionado e deve ter sua ação minimizada para prover a educação e maximizada para avaliar. Com a diminuição do Estado provedor, a sociedade civil é chamada a responsabilizarse pela educação de crianças e jovens das classes populares.

A educação assume lugar de destaque nessa reforma e constitui-se em um de seus pilares de sustentação. Por meio dela, o governo busca consolidar valores e crenças que ratificarão as mudanças em curso.

Nessa perspectiva, a escola deve (re)organizarse tendo a flexibilização como diretriz. Esta expressa-se no currículo, na avaliação, na arrecadação de recursos, na formação de professores, entre outros elementos que dão contornos à organização escolar. Mas a base sobre a qual ela se assenta pode ser apreendida por três eixos principais: gestão, formação de professores e inclusão.

A gestão tem como foco a descentralização de alguns elementos da escola, mas não de todos; ela encaminha-se, discursivamente, como sinônimo de democratização.

A municipalização aparece aí como um instrumento que retira do governo federal a responsabilidade, que é repassada principalmente aos municípios. Nesta mesma lógica (sob o discurso da democratiza- 
ção), as unidades escolares acabam por assumir a responsabilidade pela ação educativa, convertendo-se, então, em foco privilegiado da gestão. É sobre a escola que incidem as exigências pela formação de uma nova "mentalidade" política e social.

O professor e sua necessária formação aparecem como elementos decisivos no encaminhamento dessa versão de gestão. Ou seja, o professor assume o papel de gestor da educação e a sua formação deve reafirmar tal função. Para isso, o governo propõe uma formação de professores aligeirada e utilitarista, tendo por base a prática do professor.

Como expressão desse encaminhamento, apresento a formação de professores para a educação especial que, tendo como foco a inclusão, indica a formação docente como elemento-chave para a mudança na escola. Porém, como observado, a formação desse profissional mantém como suas bases teóricas aquelas que explicam o fracasso escolar pelas diferenças individuais.

Compreendida como uma política que não se restringe à educação especial, mas é expressa também por ela, a inclusão adquire status de eixo. A política de inclusão não tem como objetivo remover os mecanismos de exclusão do interior da escola. Ao contrário, sob o discurso da inclusão com a necessária aceitação das diferenças, vem consolidando a exclusão. Agora, a inclusão não ocorre quando, por razões individuais, não há condição para tal. Ou seja, voltamos ao perverso argumento da meritocracia.

Dessa maneira, esses três pontos da reforma dão contorno a uma mudança que tem por objetivo primeiro a permanência de mecanismos de exclusão na e da escola (Ferraro, 1999) de crianças e jovens oriundos das classes populares.

\section{Referências bibliográficas}

AZEVEDO, Janete M. Lins de. A educação como política pública. Campinas: Autores Associados, 1997.

BANCO MUNDIAL. Departamento de Educación y Politicas Sociales. Prioridades y estrategias para la educación. Estudio Sectorial del Banco Mundial. Washington, 1995.
BRASIL. Lei n 9.394, de 20 de dezembro de 1996. Estabelece as diretrizes e bases da educação nacional. Brasília: Ministério da Educação e do Desporto, 1996.

BRASIL. Conselho Nacional de Educação. Resolução n. 2, de 11 de setembro de 2001. Estabelece as diretrizes nacionais para a educação especial na educação básica. Brasília: Ministério da Educação, 2001.

Resolução n. 1, de 15 de maio de 2006. Institui diretrizes curriculares nacionais para o curso de pedagogia - licenciatura. Brasília: Ministério da Educação, 2006.

BOURDIEU, Pierre; PASSERON, Jean-Claude. A reprodução: elementos para uma teoria do sistema de ensino. 3. ed. Rio de Janeiro: Francisco Alves, 1992.

BUENO, José Geraldo Silveira. A educação especial nas universidades brasileiras. Brasília: MEC, SEESP, 2002.

CAMPOS, Roselane Fátima. O cenário da formação de professores no Brasil: analisando os impactos da reforma da formação de professores. Trabalho apresentado na XII Reunião Nacional da ANFOPE. Brasília, 2004. Mimeografado.

CARTOLANO, Maria Teresa Penteado. Formação do educador no curso de pedagogia: a educação especial. Cadernos Cedes - A nova LDB e as necessidades educativas especiais, Campinas, UNICAMP, ano XIX, n. 46, p. 29-40, 1998.

CEPAL/UNESCO. Educação e conhecimento: eixo da transformação produtiva com eqüidade. Brasília: IPEA; CEPAL; INEP, 1995.

CARVALHO, Mark Clark Assen de. A formação de professores para o ensino fundamental: o discurso da eterna provisoriedade. 1997. Dissertação (Mestrado em Educação) - Programa de PósGraduação em Educação: História e Filosofia da Educação, Pontifícia Universidade Católica, São Paulo, 1997.

CORREIA, José Alberto. A construção político-cognitiva da exclusão social no campo educativo. Porto, Portugal: Universidade do Porto. 2004. Mimeografado.

FERRARO, Alceu Ravanello. Diagnóstico da escolarização no Brasil. Revista Brasileira de Educação, Rio de Janeiro, ANPEd; Campinas, Autores Associados, n. 12, p. 22-47, set./out./nov./dez. 1999.

FERRARO, Alceu Ravanello; MACHADO, Nádie Christina Ferreira. Da universalização do acesso à escola no Brasil. Educação \& Sociedade, Campinas, v. 23, n. 79, p. 213-233, ago. 2002. FONSECA, Marília. O Banco Mundial e a educação: reflexões sobre o caso brasileiro. In: GENTILI, Pablo (Org.). Pedagogia da 
exclusão: crítica ao neoliberalismo em educação. Petrópolis: Vozes, 1995. p. 169-195.

FREITAS, Luiz Carlos de. Ciclo ou série? O que muda quando se altera a forma de organizar os tempos-espaços da escola? Trabalho apresentado na 27ª Reunião Anual da ANPEd. Caxambu, 2004. Mimeografado.

. A internalização da exclusão. Educação \& Sociedade, Campinas, v. 23, n. 80, p. 299-325, 2002.

GARCIA, Rosalba Maria Cardoso. Políticas públicas de inclusão: uma análise no campo de educação especial brasileira. 2004. Tese (Doutorado em Educação) - Programa de Pós-Graduação em Educação do Centro de Ciência da Educação, Universidade Federal de Santa Catarina, Florianópolis, 2004.

GIROUX, Henry; SIMON, Roger. Cultura popular e pedagogia crítica: a vida cotidiana como base para o conhecimento curricular. In: MOREIRA, Antonio Flávio; SILVA,Tomas Tadeu da (Orgs.). Currículo, cultura e sociedade. 2. ed. São Paulo: Cortez, 1995. p. 93-124.

MARTINS, José de Souza. Exclusão social e a nova desigualdade. São Paulo: Paulus, 1997.

A sociabilidade do homem simples: cotidiano e história na modernidade anômala. São Paulo: Hucitec, 2000.

MELO, Maria Tereza Leitão de. Gestão educacional: os desafios do cotidiano escolar. In: FERREIRA, Naura Syria C.; AGUIAR, Márcia Ângela da S. (Orgs.). Gestão da educação: impasses, perspectivas e compromissos. São Paulo: Cortez, 2000. p. 243-254. MICHELS, Maria Helena. A formação de professores de educação especial na UFSC (1998-2001): ambigüidades estruturais e a reiteração do modelo médico-psicológico. 2004. Tese (Doutorado em Educação) - Programa de Pós-Graduação em Educação: história, política, sociedade, Pontifícia Universidade Católica de São Paulo, São Paulo, 2004.

MENDES, Enicéia Gonçalves. Desafios atuais na formação do professor de educação especial. Revista Integração, ano 14, n. 24, p. 12-17, 2002.

NUNES, Leila Regina D’Oliveira de Paula; FERREIRA, Júlio Romero; GLAT, Rosana; MENDES, Enicéia Gonçalves. A pósgraduação em educação especial no Brasil: análise crítica da produção discente. Revista Brasileira de Educação Especial, Piracicaba, UNIMEP, v. 3, n. 5, p. 113-126, 1999.

OLIVEIRA, Dalila Andrade. A gestão democrática da educação no contexto da reforma do Estado. In: FERREIRA, Naura Syria C.; AGUIAR, Márcia Ângela da S. (Orgs.). Gestão da educação: impasses, perspectivas e compromissos. São Paulo: Cortez, 2000. p. $91-112$.

. Educação e planejamento: a escola como núcleo da gestão. In: OLIVEIRA, Dalila Andrade (Org.). Gestão democrática da educação: desafios contemporâneos. 4. ed. Petrópolis: Vozes, 2002. p. 64-104.

A reestruturação do trabalho docente: precarização e flexibilização. Educação \& Sociedade, Campinas, v. 25, n. 89, p. 1127-1144, 2004.

OZGA, Jenny. Investigação sobre políticas educacionais: terreno de contestações. Porto: Porto, 2000.

PARO, Vitor Henrique. Gestão democrática da escola pública. São Paulo: Ática, 2001.

PORTELA DE OLIVEIRA, Romualdo. A municipalização do ensino no Brasil. In: OLIVEIRA, Dalila Andrade (Org.). Gestão democrática da educação: desafios contemporâneos. 4. ed. Petrópolis: Vozes, 2002. p. 174-198.

ROSAR, Maria de Fátima Félix. A municipalização como estratégia de descentralização e de desconstrução do sistema brasileiro. In: OLIVEIRA, Dalila Andrade (Org.). Gestão democrática da educação: desafios contemporâneos. 4. ed. Petrópolis: Vozes, 2002. p. 105-140. SASSAKI, Romeu K. Inclusão: construindo uma sociedade para todos. Rio de Janeiro: WVA, 1997.

SCHEIBE, Leda. Políticas para a formação dos profissionais da educação neste início de século: análise e perspectiva. Trabalho apresentado na 26a Reunião Anual da ANPEd. Poços de Caldas, 2003. Mimeografado.

SHIROMA, Eneida Oto; MORAES, Maria Célia Marcondes de; EVANGELISTA, Olinda. Política educacional. Rio de Janeiro: DP\&A, 2000.

SHIROMA, Eneida Oto; EVANGELISTA, Olinda. O fantasma ronda o professor: a mística da competência. In: MORAES, Maria Célia Marcondes de (Org.). Iluminismo às avessas: produção de conhecimento e políticas de formação docente. Rio de Janeiro: DP\&A, 2003. p. 81-98.

SKRTIC, Thomas M. La crisis en el conocimiento de la educación especial: una perspectiva sobre la perspectiva. In: FRANKLIN, Barry M. (Comp.). Interpretación de la discapacidad: teoría e historia de la educación especial. Barcelona: Pomares-Corredor, 1996. p. 35-72.

SOARES, Maria Aparecida Leite. A educação do surdo no Brasil. Campinas: Autores Associados; Bragança Paulista: EDUSF, 1999. TOMMASI, Lílian de; WARDE, Miriam Jorge; HADDAD, Sér- 
gio (Orgs.). O Banco Mundial e as políticas educacionais. São Paulo: Cortez, 1996.

TORRES, Rosa Maria. Melhorar a qualidade da educação básica? As estratégias do Banco Mundial. In: TOMMASI, Lílian de; WARDE, Mirian Jorge; HADDAD, Sérgio (Orgs.). O Banco Mundial e as políticas educacionais. São Paulo: Cortez, 1996. p. 125-193.

. Tendências da formação docente nos anos 90. In: WARDE, Mirian Jorge (Org.). Novas políticas educacionais: críticas e perspectivas. São Paulo: PUC/SP, Programa de Estudos Pós-graduados em Educação: história e filosofia da educação, 1998. p. 173-191.

VIEIRA, Sofia Lercher. Escola - função social, gestão e política educacional. In: FERREIRA, Naura Syria C.; AGUIAR, Márcia Ângela das (Orgs.). Gestão da educação: impasses, perspectivas e compromissos. São Paulo: Cortez, 2000. p. 129-145.

WARDE, Mirian Jorge. Novas políticas educacionais: críticas e perspectivas. São Paulo: EHPS; PUCSP, 1998.

MARIA HELENA MICHELS, doutora em educação pela Pontifícia Universidade Católica de São Paulo (PUC/SP), é professora do Departamento de Estudos Especializados em Educação da Universidade Federal de Santa Catarina, atuando princi- palmente nas áreas de organização escolar e educação especial. Atualmente integra o Grupo de Estudos em Política Educacional e Trabalho - GEPETO/UFSC. Principais publicações: Paradoxos da formação de professores para a educação especial: o currículo como expressão da reiteração do modelo médico-psicológico (Revista Brasileira de Educação Especial, Marília, UNESP, v. 11, p. 255-272, maio/ago. 2005); Caminhos da exclusão: a política para a educação e a educação especial nos anos de 1990 (Ponto de Vista - Revista de Educação e Processos Inclusivos, Florianópolis, UFSC, n. 3/4, p. 73-86, jan./dez. 2002); Ambigüidades estruturais e reiteração do modelo médico-psicológico como marca da formação de professores de educação especial (Reunião Anual da ANPEd, 28., 2004. Caxambu, Anais..., Caxambu, 2004. 1 CDROM). Pesquisa em andamento: “A reorganização de redes municipais de ensino na perspectiva da educação inclusiva em Santa Catarina: formas organizativas do trabalho pedagógico e formação de professores”.E-mail: mhmichels@uol.com.br.

Recebido em janeiro de 2006 Aprovado em maio de 2006 


\section{Resumos/Abstracts/Resumens}

Maria Helena Michels

Gestão, formação docente e inclusão: eixos da reforma educacional brasileira que atribuem contornos à organização escolar

O presente texto tem por objetivo discutir a organização escolar indicada 
pela reforma educacional brasileira dos anos de 1990. Compreendendo que a escola desempenha uma função social que vai além do repasse de conhecimento, e que a reorganização capitalista coloca sobre a educação um de seus focos, buscou-se perceber como essa reforma redefine a organização escolar a partir de três pontos-chave: gestão, formação de professores e inclusão. A educação especial e a formação de seus professores aparecem como expressão dessas relações. Observando que esses pontos estão articulados entre si, procurou-se explicitar como a reforma educacional propõe mudanças que objetivam, principalmente, a manutenção de sua lógica excludente.

Palavras-chave: organização escolar; gestão; formação de professores; inclusão

Management, teacher training and inclusion: pivots of the Brazilian educational reform which attribute configurations to school organisation

The objective of this text is to discuss the school organization proposed by the Brazilian educational reform in the 1990's. Comprehending that the school performs a social function which goes beyond transmitting knowledge and that the necessary capitalist reorganization places on education one of its focuses, we sought to perceive how this reform redefines school organisation by looking at three key points: management, teacher training and inclusion. Special education and teacher training appear here as an expression of these relationships. Observing that these points are articulated, we endeavour to explain how the educational reform proposes changes whose main objective is the conservation of its exculpatory logic.

Key words: school organization; management; teacher training; inclusion.
Gestión, formación docente e inclusión: ejes de la reforma educacional brasileña que atribuyen contornos a la organización escolar El presente texto tiene por objetivo discutir la organización escolar indicada por la reforma educacional brasileña de los años 1990. Comprendendo que la escuela ejerce una función social que va más allá del repaso de conocimiento, y que la reorganización capitalista coloca sobre la educación uno de sus focos, se buscó percibir como esta reforma redefine la organización escolar a partir de tres puntos claves: gestión, formación de profesores e inclusión. La educación especial y la formación de sus profesores aparecen como una expresión de esas relaciones. Observando que estos puntos están articulados entre sí, se buscó explicitar como la reforma educacional propone cambios que tienen por objeto, principalmente, la manutención de su lógica excluyente.

Palabras claves: organización escolar; gestión; formación de profesores; inclusión 